\title{
Trabalho em integração com a vida: trajetórias de trabalhadores da atenção básica à saúde e a construção de sua identidade profissional
}

\author{
Selma Aparecida Caselli Martins ${ }^{\mathrm{I}}$ e Edite Krawulski ${ }^{\mathrm{II}, 1}$ \\ ${ }^{\text {I }}$ Secretaria de Estado da Saúde de Santa Catarina (Florianópolis, SC) \\ ${ }^{\text {II }}$ Universidade Federal de Santa Catarina (Florianópolis, SC)
}

\begin{abstract}
Este artigo resulta de um recorte de investigação científica de caráter qualitativo focalizando o cotidiano de trabalho de profissionais da atenção básica à saúde na cidade de Florianópolis. Partiu-se do pressuposto de que as trajetórias profissionais vivenciadas por esses trabalhadores, antes e durante sua permanência no quadro funcional da prefeitura municipal, consistem em elementos integrantes e essenciais da construção de sua identidade como profissionais da saúde. Foram entrevistados dez profissionais de diferentes categorias funcionais que atuam em diferentes centros de saúde. Os resultados, analisados com base na análise do discurso, acerca de suas trajetórias profissionais e dos sentidos atribuídos ao trabalho, mostraram uma estreita ligação entre o trabalho e a vida desses profissionais. Essa ligação estreita decorre da profunda identificação com as atividades de trabalho, bem como das iniciativas de qualificação profissional integradas às suas experiências de vida. Decorre, ainda, dos diferentes sentidos atribuídos ao trabalho, abrangendo desde uma valorização da dimensão individual/particular determinante de suas trajetórias profissionais até valores da dimensão humano/genérica, como as concepções sobre o serviço público onde atuam, reconhecendo-se como participantes de um coletivo de trabalho no qual as duas dimensões encontram-se entrelaçadas.
\end{abstract}

Palavras-chave: Trabalho, Atenção básica à saúde, Trajetórias profissionais, Identidade profissional.

Work and life integration: trajectories of basic health care workers and the construction of their professional identity

This paper results from an outline of a scientific investigation with a qualitative design focusing on the daily work of basic health care professionals in the city of Florianopolis. It started from the assumption that the professional trajectories experienced by these workers, before and during their tenure as municipal employees, consist in constituent and essential elements for the construction of their identity as health care professionals. Ten professionals from different functional categories who work at different health centers were interviewed. The results, analyzed having discourse analysis as a basis, on their professional trajectories and the meanings they attribute to work, showed a close relationship between their work and life. This close binding comes from the deep identification with their work activities, as well as from their professional qualification initiatives connected to their life experiences. It also results from different meanings attributed to work, comprising both an appreciation of the individual/personal dimension determining their professional trajectories and values from the human/generic dimension, such as conceptions on the public service where they work, recognizing themselves as participants of a working team in which both dimensions are interwoven.

Keywords: Work, Basic health care, Professional trajectories, Professional identity.

\section{Introdução}

Esing ste artigo é parte de investigação científica junto ao Programa de Pós-Graduação da Universidade Federal de Santa Catarina (UFSC), desenvolvida em centros de saúde do município de Florianópolis durante o ano de 2010, cujo objetivo principal consistiu em buscar compreender o cotidiano de trabalho de profissionais da atenção básica à saúde. A priorização da análise da temática relativa ao cotidiano e, especificamente, aos sentidos atribuídos ao trabalho por esses profissionais em uma perspectiva sócio-histórica permitiu identificar quais

1 Professora da Universidade Federal de Santa Catarina. Centro de Filosofia e Ciências Humanas. Programa de Pós-Graduação em Psicologia. 
aspectos individuais e/ou particulares encontravam-se entrelaçados em seus discursos acerca do cotidiano de trabalho.

Foram destacados na investigação três núcleos de significação (Martins, 2011), procurando abranger o que se pretendia responder através do estudo, seguidos de elementos encontrados a partir da análise, a saber: trajetórias de trabalho dos profissionais - a integração da vida com o trabalho; concepções e sentimentos em relação ao trabalho - emoção e intensidade afetiva, criatividade, saberes tácitos e estratégias defensivas no combate às dissonâncias no cotidiano; políticas públicas em saúde - o que se conhece, o que se faz na prática e o que se deseja fazer. Os núcleos foram nomeados de modo a abranger o que se pretendia mostrar em cada um deles, tendo-se, porém, a consciência de sua limitação para expressar todos os elementos encontrados no campo. Neste artigo, procuramos nos ater aos aspectos que caracterizaram o primeiro núcleo de significação da pesquisa, dando ênfase às trajetórias profissionais dos sujeitos como parte do processo de construção de sua identidade profissional.

As trajetórias profissionais desses trabalhadores foram investigadas, tanto do ponto de vista das ocupações anteriores ao seu ingresso no quadro funcional da Prefeitura Municipal de Florianópolis (PMF) quanto em relação aos deslocamentos realizados entre as unidades de saúde municipais. Por trajetórias de trabalho entende-se, aqui, a compreensão dos caminhos que os sujeitos da pesquisa percorreram e o conjunto de experiências vivenciadas em suas vidas profissionais até o momento como servidores do setor público, sem perder de vista as especificidades relativas à natureza e ao contexto do trabalho que realizam na atenção básica à saúde.

A atenção básica à saúde é definida como a operacionalização da atenção primária de saúde no âmbito do Sistema Único de Saúde (SUS) e compreende um conjunto de ações prestadas às pessoas e à comunidade com vistas à promoção da saúde e prevenção de doenças, bem como ao tratamento e reabilitação no primeiro nível de atenção dos sistemas locais de saúde (Brasil, 2000). Nesse nível, o trabalho abrange uma singularidade, em função de características como a complexidade e a multidimensionalidade dos próprios elementos presentes no processo de trabalho ${ }^{2}$. A complexidade se desenha pelas múltiplas e intrincadas relações envolvidas, verificadas no processo, e a multidimensionalidade se caracteriza por questões que circunscrevem o corporal, o social e o subjetivo de todos os envolvidos, sejam estes os profissionais que atuam direta ou indiretamente com o usuário ou o próprio usuário, bem como os representantes do órgão gestor da saúde e da comunidade.

Ao representar o primeiro nível de atenção à saúde do indivíduo e da comunidade, a atenção básica direciona o trabalho de todos os demais níveis do sistema de saúde e, assim sendo, para que atinja, de fato, seus propósitos, deve estar articulado a variáveis do meio físico e social no qual as pessoas vivem e trabalham, e não somente focar o objeto imediato de ausência de doença. A busca dessa articulação rompe com a compreensão anteriormente vigente, segundo a qual saúde era sinônimo de ausência de doenças físicas e mentais, determinando aos serviços de saúde privilegiar em sua organização a atenção médica curativa (Fermino, Patrício, Krawulski \& Sisson, 2009).

No âmbito da saúde pública, o trabalho está sob a influência - a começar pela formulação das políticas públicas, especialmente aquelas que regem a criação do $\mathrm{SUS}^{3}$-, de macromudanças políticas, econômicas e sociais ocorridas na sociedade, bem como dos padrões

2 A Portaria n. 648 (Brasil, 2006), do Ministério da Saúde, descreve minuciosamente as características do processo de trabalho na atenção básica à saúde.

3 Criado a partir da Constituição de 1988 e em vigência desde 1990, com a aprovação: da Lei n. 8.080/90, que disciplina a descentralização político-administrativa do SUS, enfatiza seus aspectos de gestão e financiamento, regulamenta as condições para promoção, proteção e recuperação da saúde e a organização e funcionamento de serviços correspondentes; e da Lei n. 8.142/90, que regulamenta a participação da comunidade, bem como as transferências intergovernamentais de recursos financeiros (Brasil, 2005). 
culturais e do paradigma de conhecimento hegemônico em dado momento histórico. Dessa forma, tanto as formas de organização do trabalho como a produção dos conhecimentos e a formação dos profissionais em saúde são historicamente delimitadas. $\mathrm{O}$ modelo de organização do trabalho em saúde, originado a partir da estruturação do modo capitalista de produção foi sendo caracterizado como um trabalho fragmentado em diversas profissões de áreas afins, dividindo espaços físicos na rede pública e privada, com características de trabalho coletivo e sob a hegemonia do modelo biomédico (Elman, 2005). O campo de atuação em saúde constituiu-se, portanto, desde sua origem, baseado e centrado no médico, orbitado pelas outras profissões servindo de facilitadoras para a retroalimentação de um modelo que viria a se constituir hegemonicamente e com características de trabalho coletivo.

A origem da modalidade de trabalho com características coletivas remonta, segundo Antunes (1999), ao surgimento do toyotismo, invertendo a relação de trabalho individual para trabalho coletivo, onde entram em ação a necessidade da qualificação e a polivalência do profissional. No âmbito do trabalho coletivo em saúde, como aponta Gonçalves (1994), há uma "micropolítica", pois os saberes tecnológicos (como a clínica e a epidemiologia) podem adquirir, no mesmo serviço, formatos totalmente diferentes dependendo de quem os coloca em prática e da organização do modelo assistencial. Para além das máquinas e do conhecimento técnico, portanto, há algo "nuclear no trabalho em saúde", que consiste nas relações entre os sujeitos e suas ações no cotidiano.

Essa permanente atuação no cenário de produção da saúde Gonçalves (1994, citado por Merhy \& Franco, 2008, p. 350) chama de "micropolítica do trabalho vivo em ato", reconhecendo que o espaço onde se produz saúde "é um lugar onde se realizam também os desejos e a intersubjetividade, que estruturam a ação dos sujeitos, trabalhador e usuário, individual e coletivo". Vistos desse modo, no lugar onde se produz saúde, o tipo de trabalhador e de coletivo de trabalho nele inseridos fazem total diferença, pois "fazem de suas liberdades micropolíticas formas de ação ético-política direcionadas" (Gonçalves, 1994, citado por Merhy \& Franco, 2008, p. 350). Assim, conforme compreendem o que é o "outro", modificam seus modos de construir o cuidado, intervindo nas formas de uso de suas ferramentas, conhecimento e equipamentos, configurando um contexto de contínua reestruturação produtiva, sempre centrada na ideia de necessidade de mudanças nos processos de trabalho e no modo de produzir o cuidado em saúde.

As peculiaridades, tanto das trajetórias dos trabalhadores do campo da saúde pública como dos processos de trabalho, remetem à necessidade de considerar as relações entre trabalho e identidade.

\section{Trabalho e identidade}

O trabalho surgiu na história da humanidade com a concepção de intermediar o atendimento às necessidades imediatas da sobrevivência, passando, apenas nos últimos séculos, a partir de determinadas circunstâncias históricas, a, gradualmente, ser criador de riquezas e totalmente investido de conotação econômica (Coutinho, Krawulski \& Soares, 2007). "Então, o homem passou a ser visto como um componente de uma força de trabalho e se viu transformado de indivíduo em trabalhador: o trabalho passou a significar um instrumento do valor e da dignidade humana..." (Krawulski, 1998, p. 12).

Procurar compreender quem são os trabalhadores que se inserem nas organizações, segundo Coutinho (2006), nos remete à questão da identidade, resgatada por diversos autores das ciências humanas visando à compreensão da relação que envolve os aspectos da identidade com o trabalho na contemporaneidade, entre eles: Coutinho (2006, 2009) e Coutinho, 
Krawulski e Soares (2007). Esses estudos partem do princípio geral de que a identidade se constrói em uma relação dialética entre o indivíduo e a sociedade, na qual cada indivíduo se identifica e se transforma a partir do outro (Coutinho, 2006).

A assimilação da realidade se dá através dessa relação, como também a capacidade de realizar uma reprodução ativa de sua experiência social (Jacques, 1993). Para autores como Berger e Luckmann (1999), cada sujeito exterioriza e simultaneamente interioriza seu modo de ser no mundo, sendo que esse processo efetiva-se através da socialização primária e secundária dos indivíduos. Martin-Baró (1988, p. 115) conceitua socialização como sendo "processos psicossociais nos quais o indivíduo se desenvolve historicamente como pessoa e como membro de uma sociedade" e implica os processos de desenvolvimento histórico, da identidade pessoal e da identidade social. Trata-se de um processo histórico decorrente de situações históricas concretas não previamente definidas, portanto, mutáveis de acordo com o tipo de sociedade, grupo ou classe social considerados. A identidade pessoal é construída por cada um a partir de características singulares, porém, através das relações sociais, sendo a sociedade "um elemento constitutivo e não externo a essa identidade. Por outro lado, é através da socialização que o indivíduo é marcado pelas características do grupo social e da sociedade em que ele está inserido, constituindo assim, sua identidade social" (Coutinho, 2006, p. 163).

O termo identidade social tem sido usado na psicologia social, segundo Jacques (1996), referindo-se ao pertencimento a determinado grupo social, bem como à carga afetiva que isso implica.

Enquanto apresentada como um processo dialético, a identidade social facilita a incorporação de valores e normas do grupo social, implica uma participação ativa do sujeito na construção da identidade grupal e afeta o contexto histórico em que ocorrem estas relações concretas (Jacques, 1996, p. 44).

O pertencimento a grupos sociais específicos carrega em si noções de identidade que nos identificam, igualam e, ao mesmo tempo, diferenciam-nos de outros grupos. Para Ciampa (1984), os grupos se definem através das relações estabelecidas entre seus membros, suas práticas e suas ações no mundo. Nessas práticas incluem-se as ações de trabalho, que, por sua vez, encontram-se delimitadas pela inserção material e histórica, e, portanto, sujeitas a um processo permanente de transformações do próprio sujeito que as realiza.

No atual contexto, marcado por fragmentações, descontinuidades e efemeridades, certamente a constituição das identidades torna-se um processo bem mais complexo do que nas sociedades modernas, favorecendo a fragmentação dos sujeitos (Coutinho et al., 2007) e, nesse sentido, as identidades devem ser compreendidas como identificações em curso (Santos, 2001). O sujeito busca reconfigurar os processos identitários, advindos de suas experiências laborais, de modo a articular alguma continuidade na mudança, pois

[...] continua procurando organizar suas experiências cotidianas em um conjunto relativamente estável, que pode ser percebido como o seu eu. É a continuidade da busca pela construção de uma biografia que tenha e faça sentido, para o próprio sujeito e para o mundo em seu entorno (Coutinho et al., 2007, p. 19).

A busca pela compreensão das continuidades e das mudanças nos modos de ser trabalhador na contemporaneidade pode ser levada a cabo por meio de estratégias voltadas à investigação da trajetória profissional. A pluralidade desses modos de ser justifica "[...] o interesse teórico e metodológico pelas trajetórias ocupacionais de trabalhadores" (Guimarães \& Hirata, 2006, p. 12). A partir de uma série de estudos sobre sujeitos com diferentes formas de inserção no atual contexto produtivo, a investigação das trajetórias ocupacionais tem sido considerada uma estratégia promissora nesse sentido (Coutinho, 2009; Veriguine, Basso, Krawulski, Coutinho \& Soares, 2011), em vista da necessidade de encontrar formas que 
possam apreender a complexidade das relações entre as dimensões objetivas e subjetivas do trabalho na atualidade de acordo com as mudanças por que passa o mundo do trabalho a partir das transformações nos contextos produtivos. As trajetórias identitárias constituem-se, segundo Coutinho (2009), em uma estratégia de investigação capaz de dar conta do caráter processual da condição humana relativa ao trabalho contemporâneo.

A busca pela compreensão das trajetórias identitárias no estudo realizado teve o caráter de atribuir um sentido singular e processual às trajetórias ocupacionais e/ou profissionais destacadas pelos sujeitos em seus relatos orais acerca de seu trabalho. Os termos trajetórias ocupacionais e/ou trajetórias profissionais ou de trabalho são utilizados aqui com o mesmo significado, de modo a caracterizar os caminhos profissionais percorridos previamente ao ingresso desses sujeitos no serviço público municipal, sendo denominados daqui em diante trajetórias profissionais. A identificação das trajetórias desses profissionais da atenção básica à saúde abriu espaço para uma discussão acerca das singularidades dos sujeitos envolvidos no processo de construção do trabalho na saúde nesse nível de atendimento. Ao mesmo tempo, permitiu constatar que esses sujeitos fazem parte de um coletivo de trabalho no qual suas singularidades encontram-se a serviço de necessidades inerentes à construção de um processo de trabalho definido sócio-historicamente a partir de suas práticas cotidianas.

\section{Método}

O estudo é de natureza qualitativa, tendo como objeto o trabalho de profissionais da atenção básica à saúde em Florianópolis. A concepção de pesquisa em ciências humanas a partir da perspectiva sócio-histórica "implica compreendê-la como uma relação entre sujeitos possibilitada pela linguagem" (Freitas, Souza \& Kramer, 2007, p. 29). Desse modo, a própria adoção do termo sujeito e não objeto em referência à pessoa investigada reflete a posição do pesquisador quanto à sua forma de focalizar e compreender a realidade, permitindo-lhe um espaço de participação ativa no processo (Gonzalez Rey, 1999). De acordo com essa visão, foram utilizadas como recursos metodológicos entrevistas semiestruturadas do tipo reflexivo, baseadas no conceito de reflexividade, entendido como o caráter recorrente da interação, buscando construir uma condição de horizontalidade de posições, minimizando diferenças culturais e de compreensão (Szymanski, 2000). Neste estudo, o recurso da reflexividade foi adaptado às suas condições de operacionalização, segundo as quais se realizou apenas um encontro com cada um dos sujeitos entrevistados. Sendo assim, foram sendo realizadas devolutivas orais, com o objetivo de refletir a fala dos sujeitos, no ato de cada questionamento realizado. A interpretação dos dados foi baseada na análise de discursos orais segundo o modelo de núcleos de significação proposto por Aguiar e Ozella (2006). O projeto de pesquisa foi aprovado pelo Comitê de Ética em Pesquisa da UFSC e da Secretaria Municipal de Saúde de Florianópolis.

O campo pesquisado constituiu-se por centros de saúde que prestam o atendimento no nível da atenção básica à saúde da Prefeitura Municipal de Florianópolis. Esses centros de saúde são compostos por profissionais que integram o quadro denominado Estratégia de Saúde da Família (ESF), os quais foram sendo agregados às equipes que ali já trabalhavam antes da implantação do Programa de Saúde da Família (PSF) ${ }^{4}$ e que desenvolvem a assistência em nível de atenção básica. Foram sujeitos do estudo profissionais ocupantes de categorias funcionais que atuam na atenção básica nos centros de saúde, independente de fazer parte oficialmente das equipes de ESF. As categorias citadas incluem médicos generalistas e de família, pediatras,

4 O PSF teve sua implantação gradativa após aprovação pelo Conselho Municipal de Saúde a partir de 1994 e é tido como uma das principais estratégias de reorganização dos serviços e de reorientação das práticas profissionais nesse nível de assistência, visando à integração desta com a promoção da saúde, prevenção de doenças e reabilitação (Brasil, 2006). 
ginecologistas, odontólogos, enfermeiros, técnicos de enfermagem, auxiliares de enfermagem, técnicos administrativos, auxiliares de consultório dentário e agentes comunitários de saúde. Agregam-se a estes outros profissionais considerados especialistas, os quais realizam apoio matricial em áreas específicas, compondo os Núcleos de Atenção à Saúde da Família (NASF) ${ }^{5}$. Estão entre esses especialistas: psiquiatra, geriatra, psicólogo, nutricionista, assistente social e educador físico, os quais circulam pelas unidades de saúde, em uma proposta de trabalho interdisciplinar, objetivando "assegurar retaguarda especializada a equipes e profissionais encarregados da atenção a problemas de saúde” (Campos \& Domitti, 2007, p. 399).

Inicialmente foi realizado um levantamento, em conjunto com profissional do setor de pessoal, diretamente no banco de dados da própria secretaria, em abril de 2010. Esse procedimento possibilitou a obtenção de uma listagem de cada um dos centros de saúde, com seus respectivos servidores citados nominalmente, seus respectivos cargos e unidades de lotação.

Participaram da pesquisa 10 profissionais, selecionados de modo a garantir pelo menos um representante de cada categoria profissional. Alguns critérios foram definidos previamente e cumpridos, a saber: representação dos cinco Distritos Sanitários de Saúde do município, englobando 10 diferentes centros de saúde, os quais foram selecionados, na medida do possível, procurando contemplar unidades representativas das diversidades populacionais, com localizações desde as mais centrais às mais periféricas do município. Quanto aos sujeitos, todos eram funcionários da PMF, e a prioridade de escolha foi dada a profissionais que trabalham diariamente na mesma unidade de saúde, fazendo parte do seu cotidiano e processo de trabalho. Foram entrevistados um médico de família, uma enfermeira, uma dentista, uma técnica de enfermagem, um auxiliar de enfermagem, uma atendente de consultório odontológico (ACO), uma agente comunitária de saúde (ACS), um técnico administrativo, uma médica pediatra e uma psicóloga ${ }^{6}$.

\section{Resultados: caracterização dos sujeitos e suas trajetórias profissionais}

Elaborou-se uma caracterização dos sujeitos através de uma síntese a partir das suas falas, como consta no Quadro 1, de modo a situar o leitor quando os relatos acerca de suas trajetórias forem mencionados de modo particularizado. Por uma questão ética, para preservar o anonimato dos sujeitos e evitar uma possível associação às unidades de trabalho, foram-lhes atribuídas letras aleatórias do alfabeto, antes da descrição dos cargos ou categorias funcionais que ocupam na Secretaria Municipal de Saúde da Prefeitura de Florianópolis (SMS/PMF). Nesse quadro constam as categorias funcionais ou cargos ocupados, o sexo, a formação escolar/acadêmica, a experiência prévia à entrada na PMF, a forma e o tempo de ingresso no serviço público, o tempo de trabalho no centro de saúde atual e a capacitação para a função.

\footnotetext{
5 Segundo o artigo 1ำ da Portaria n. 154, de 24 de janeiro de 2008, os NASF têm por objetivo “ampliar a abrangência e o escopo das ações da atenção básica, bem como sua resolubilidade, apoiando a inserção da Estratégia de Saúde da Família na rede de serviços e o processo de territorialização e regionalização a partir da atenção básica” (Brasil, 2008).

6 Embora essa profissional não trabalhasse diariamente na mesma unidade de saúde, foi incluída na pesquisa aleatoriamente, como categoria profissional especialista do NASF, a fim de completar os 10 sujeitos de pesquisa previstos e garantir a representação de 2 profissionais de cada distrito de saúde, já que as outras 9 categorias principais presentes diariamente nas unidades de saúde já estavam representadas.
} 


\section{Quadro 1: Caracterização dos sujeitos}

\begin{tabular}{|c|c|c|c|c|c|c|c|}
\hline $\begin{array}{l}\text { Sujeito - } \\
\text { Cargo ocupado }\end{array}$ & $\begin{array}{l}\text { Sexo/ } \\
\text { Idade }\end{array}$ & $\begin{array}{l}\text { Formação } \\
\text { escolar/ } \\
\text { acadêmica }\end{array}$ & $\begin{array}{l}\text { Experiência } \\
\text { profissional } \\
\text { prévia }\end{array}$ & $\begin{array}{l}\text { Forma de } \\
\text { ingresso } \\
\text { na PMF }\end{array}$ & $\begin{array}{l}\text { Tempo } \\
\text { PMF }\end{array}$ & $\begin{array}{l}\text { Tempo } \\
\text { no CS } \\
\text { atual }\end{array}$ & $\begin{array}{l}\text { Capacitação para a } \\
\text { função }\end{array}$ \\
\hline $\begin{array}{l}\text { C-Agente } \\
\text { Comunitário } \\
\text { Saúde }\end{array}$ & F 52 & $\begin{array}{l}2^{\circ} \text { grau } \\
\text { completo }\end{array}$ & $\begin{array}{l}\text { Promoção } \\
\text { de vendas }\end{array}$ & $\begin{array}{l}\text { Processo } \\
\text { seletivo } \\
\text { CLT/AFL } \\
\text { OV }\end{array}$ & 10 anos & 9 anos & $\begin{array}{l}\text { "Uma colega ensinava } \\
\text { para outra", hoje faz curso } \\
\text { de formação inicial para } \\
\text { os ACS }\end{array}$ \\
\hline $\begin{array}{l}\text { F-Médico de } \\
\text { Família }\end{array}$ & $\begin{array}{l}\mathrm{M} \\
30 / 40^{*}\end{array}$ & UFRJ/ 2001 & $\begin{array}{l}\text { HG, } \\
\text { Ambulatório } \\
\text { e pronto- } \\
\text { atendimento }\end{array}$ & $\begin{array}{l}\text { Processo } \\
\text { seletivo } 1 \\
\text { ano, } \\
\text { concurso } \\
\text { há } 2\end{array}$ & 3 anos & 2 anos & $\begin{array}{l}\text { Especialização em } \\
\text { medicina de família }\end{array}$ \\
\hline $\begin{array}{l}\text { E - Enfermeira } \\
\text { PSF }\end{array}$ & $\begin{array}{l}\mathrm{F} \\
40 / 50^{*}\end{array}$ & UFSC/1991 & $\begin{array}{l}\text { Serviços } \\
\text { domésticos }\end{array}$ & $\begin{array}{l}\text { Concurso } \\
\text { público }\end{array}$ & 18 anos & 8 anos & $\begin{array}{l}\text { Curso introdutório de } \\
\text { saúde família, } \\
\text { capacitações a novos } \\
\text { programas e coordenação }\end{array}$ \\
\hline $\begin{array}{l}\text { D - Dentista } \\
\text { PSF }\end{array}$ & F 41 & UFSC/1990 & $\begin{array}{l}\text { Clínica } \\
\text { privada e } \\
\text { PM } \\
\text { Canelinha }\end{array}$ & $\begin{array}{l}\text { Concurso } \\
\text { público }\end{array}$ & 18 anos & 4 anos & $\begin{array}{l}\text { Especialização em } \\
\text { dentística e em Saúde da } \\
\text { família }\end{array}$ \\
\hline $\begin{array}{l}\mathrm{T}-\text { Técnico } \\
\text { enfermagem } \\
\text { PSF }\end{array}$ & F 52 & $\begin{array}{l}2^{\mathrm{o}} \text { grau } \\
\text { completo } \\
\text { Curso técnico } \\
\text { enfermagem }\end{array}$ & $\begin{array}{l}\mathrm{HG} \mathrm{e} \\
\text { maternidade }\end{array}$ & $\begin{array}{l}\text { Celetista } 2 \\
\text { anos, } \\
\text { estatutária } \\
18 \text { anos }\end{array}$ & 20 anos & 3 anos & $\begin{array}{l}\text { Atualização sobre } \\
\text { curativos e vacinas }\end{array}$ \\
\hline $\begin{array}{l}\mathrm{R} \text { - Técnico } \\
\text { administrativo }\end{array}$ & $\begin{array}{l}\mathrm{M} \\
30 / 40 *\end{array}$ & $\begin{array}{l}\text { Curso superior } \\
\text { em } \\
\text { administração/ } \\
1996\end{array}$ & $\begin{array}{l}\text { Empresariad } \\
\text { o seguros, } \\
\text { bancose e } \\
\text { voluntariado } \\
\text { em HG }\end{array}$ & $\begin{array}{l}\text { Concurso } \\
\text { público }\end{array}$ & $\begin{array}{l}\text { 1ano } 8 \\
\text { meses }\end{array}$ & 3 meses & $\begin{array}{l}\text { Treinamento em sistemas, } \\
\text { informação e } \\
\text { atendimento }\end{array}$ \\
\hline $\begin{array}{l}\text { A - Auxiliar de } \\
\text { enfermagem }\end{array}$ & M 51 & $\begin{array}{l}2^{\mathrm{o}} \text { grau } \\
\text { incompleto } \\
\text { Curso de } \\
\text { auxiliar de } \\
\text { enfermagem }\end{array}$ & $\begin{array}{l}\text { Entrou } \\
\text { direto na } \\
\text { PMF }\end{array}$ & $\begin{array}{l}\text { Indicação } \\
\text { política na } \\
\text { época, } \\
\text { hoje } \\
\text { estatutário }\end{array}$ & 31 anos & 8 anos & $\begin{array}{l}\text { Curso de auxiliar de } \\
\text { enfermagem e socorrista } \\
\text { do corpo de bombeiros }\end{array}$ \\
\hline $\begin{array}{l}\text { O - Atendente } \\
\text { Consultório } \\
\text { Odontológico }\end{array}$ & F 64 & $\begin{array}{l}\text { Ensino } \\
\text { fundamental }\end{array}$ & $\begin{array}{l}\text { Lavoura e } \\
\text { Serviços } \\
\text { domésticos }\end{array}$ & $\begin{array}{l}\text { Indicação } \\
\text { política, } \\
\text { hoje } \\
\text { estatutária }\end{array}$ & 30 anos & 30 anos & $\begin{array}{l}\text { Treinamento no INSS } \\
\text { para atendente de enf; } \\
\text { para a função de ACO: "o } \\
\text { doutor me ensinou" }\end{array}$ \\
\hline $\begin{array}{l}\text { M- Pediatra } \\
\text { PSF }\end{array}$ & F 54 & UFSC / 1982 & $\begin{array}{l}\text { Entrou } \\
\text { direto na } \\
\text { PMF }\end{array}$ & $\begin{array}{l}\text { Celetista, } \\
\text { hoje } \\
\text { estatutária }\end{array}$ & 26 anos & 4 anos & Estágio em pediatria \\
\hline $\begin{array}{l}\text { P - Psicóloga } \\
\text { NASF }\end{array}$ & F 26 & UFSC/ 2008 & $\begin{array}{l}\text { Clínica } \\
\text { privada }\end{array}$ & $\begin{array}{l}\text { Contrato } \\
\text { temporário }\end{array}$ & 4 meses & 4 meses & Especialização em TCC \\
\hline
\end{tabular}

* faixa etária estimada

Como os dados apontaram, as trajetórias dos sujeitos acabam por estabelecer uma relação de identidade com o trabalho desenvolvido no cotidiano; achados da pesquisa relativos às perguntas "quem são estes profissionais?" e "em que contexto de trabalho se inserem?" mostraram um imbricamento das dimensões singular e coletiva desses sujeitos, que os insere em um contexto de trabalho e de vida interligados no qual essa relação se estabelece. A narrativa de F mostra de modo inequívoco essa interligação apontada entre a vida e o trabalho: 
Eu faço parte de um grupo muito seleto de pessoas que têm o trabalho e a vida como faces de uma mesma coisa ( $\mathrm{F}$ - médico de família).

Ele se percebe como parte de um grupo de pessoas cuja vida e trabalho mantêm uma relação de identidade que os caracteriza como um "grupo". Nesse caso, refere-se a um grupo de trabalho cuja identidade se constrói em uma relação dos indivíduos e o trabalho na sociedade à qual pertencem transformando-se dialeticamente. Afirmar que trabalho e vida são "faces de uma mesma coisa" que os define como um grupo seleto implica reconhecer-se a partir de suas práticas e, ao mesmo tempo, colocar uma carga afetiva nessa relação de pertencimento a esse grupo. Esta constatação remete ao conceito de identidade social já mencionado por Jacques (1996), no qual uma carga afetiva encontra-se presente nessa relação de pertencimento a determinado grupo social. Esse pertencimento a grupos específicos, para Ciampa (1984), é capaz, ao mesmo tempo, de nos identificar, igualar e diferenciar de outros grupos.

Para Martin-Baró (1988, p. 117), os processos de construção da identidade pessoal e social não se separam: "Não há identidade pessoal que não seja ao mesmo tempo e da mesma forma identidade social". Ciampa $(1984,1987)$, por sua vez, concebe a identidade como concretude, metamorfose e fenômeno social. Em suas palavras,

[...] a identidade como concreto está sempre se concretizando [...] é a síntese de múltiplas e distintas determinações, o desenvolvimento da identidade de alguém é determinado pelas condições históricas, sociais, materiais dadas, aí incluídas condições do próprio individuo. [...] Dessa maneira, a concretude da identidade é sua temporalidade: passado, presente e futuro (Ciampa, 1987, p. 198).

Ciampa (1987) afirma, ainda, que, ao se considerar a temporalidade como interpenetrações de passado, presente e futuro, considera-se também a questão da diferença, excluindo a identidade como mesmice, posto ser vista como metamorfose. Em outra passagem, Ciampa (1984) afirma a identidade como um fenômeno eminentemente social, relacionando sua construção às relações estabelecidas com a prática e com as ações, enfim, com o trabalho que é realizado.

Também para Jacques (2006), a importância do homo faber no mundo contemporâneo é uma justificativa para a associação entre identidade e trabalho, oriunda de uma tradição que confere ao papel social uma importância na constituição da identidade. Concebe a autora que o exercício de certas atividades objetivadas temporalmente, assim como o convívio com determinadas relações sociais em determinado momento histórico, constituem "modos de ser" (Jacques, 2006, p. 156) que qualificam os pares como semelhantes, apesar das diferenças, caracterizando alguns espaços de trabalho e/ou categorias profissionais com suas qualificações, sendo incorporados como constitutivos da identidade. Ainda em sua concepção, o termo identidade social tem sido empregado no campo da psicologia social ao referir-se

[...] à consciência de pertencer a determinado grupo social e à carga afetiva que essa pertença implica. Enquanto apresentada como um processo dialético, a identidade social facilita a incorporação de valores e normas do grupo social, implica uma participação ativa do sujeito na construção da identidade grupal e afeta o contexto histórico em que ocorrem estas relações concretas (Jacques, 1996, p. 44).

Pertencer a um grupo com uma identidade não significa que seus membros precisem ter algo em comum individualmente, mas, sim, que o grupo em si mantenha uma unidade de conjunto que o defina perante outros grupos (Martin-Baró, 1988). Percebeu-se que esses sujeitos integram determinado grupo social, nesse caso grupo de trabalho, caracterizado por práticas laborais e contextualizado historicamente como coletivo que os identifica como semelhantes, mas também objetivam suas atividades de trabalho temporal e singularmente a partir de suas concepções individuais. Partindo desse pressuposto, atentou-se nesta análise para 
elementos que aproximam os sujeitos enquanto parte de um processo identificatório relacionado à sua inserção no mundo do trabalho especificamente na área da saúde, como também para aqueles particulares, próprios de suas vivências e trajetórias individuais.

Aspectos relativos ao modo particular como eles relacionam-se com seu trabalho emergiram com frequência em suas narrativas, expressando a centralidade do trabalho em suas vidas. Apesar das maneiras singularmente colocadas, percebeu-se a indissociabilidade entre uma instância e outra, isto é, entre a vida e o trabalho: as narrativas sobre o trabalho de modo geral e sobre os sentidos do trabalho especificamente na atenção básica à saúde mostraram um vínculo estreito entre uma dimensão e outra, como se o trabalho que realizam estivesse completamente incorporado à vida e, consequentemente, à sua identidade.

O trabalho me engrandece, é minha vida, é minha finalidade, ele me realiza, aquilo que você faz, o meu dia a dia ( $\mathrm{T}$ - técnica de enfermagem).

Tem uma integração muito grande entre o que eu faço, quer dizer, tem coisas que eu faço porque eu gosto, mas tem coisas que eu faço porque eu acredito, quer dizer, é muito pouco funcional, o trabalho não é uma forma de ganhar dinheiro para subsistir fora do trabalho, ele permeia a vida. [...] Trabalhar como profissional de saúde te obriga de alguma maneira a integrar um pouco a tua formação pessoal com a tua formação profissional ( $\mathrm{F}$ - médico de família).

À luz do conceito de identidade como fenômeno social, segundo Ciampa (1984, p. 64),

[...] o conhecimento de si é dado pelo reconhecimento recíproco dos indivíduos identificados através de um determinado grupo social que existe objetivamente, com sua história, suas tradições, suas normas, seus interesses, etc. [...] um grupo existe objetivamente: através das relações que estabelecem seus membros entre si e com o meio onde vivem, isto é, pela sua prática, pelo seu agir - num sentido amplo, pelo seu trabalho.

Observou-se uma profunda identificação desses sujeitos com suas atividades de trabalho, fazendo parte desse processo identificatório suas respectivas trajetórias profissionais, bem como suas diversificadas qualificações integradas às suas experiências de vida. A maioria teve sua trajetória profissional relacionada à área da saúde desde o início da carreira, embora nem todos a tenham iniciado na atenção básica, como apresentado no Quadro 2. Diversos sujeitos tiveram experiências de trabalho anteriores ou concomitantes na área privada, atuando em hospitais, clínicas de atendimento ambulatorial ou em consultório particular. A respeito dessas experiências, há uma tendência, corroborada por autores como Spagnuolo e Guerrini (2004-2005), no sentido de apontar que grande parte dos profissionais de saúde inicia sua carreira em instituições e/ou em níveis de atenção nas quais o modelo tradicional de saúde é predominante, como hospitais e ambulatórios. 


\section{Quadro 2: Trajetória profissional dos sujeitos}

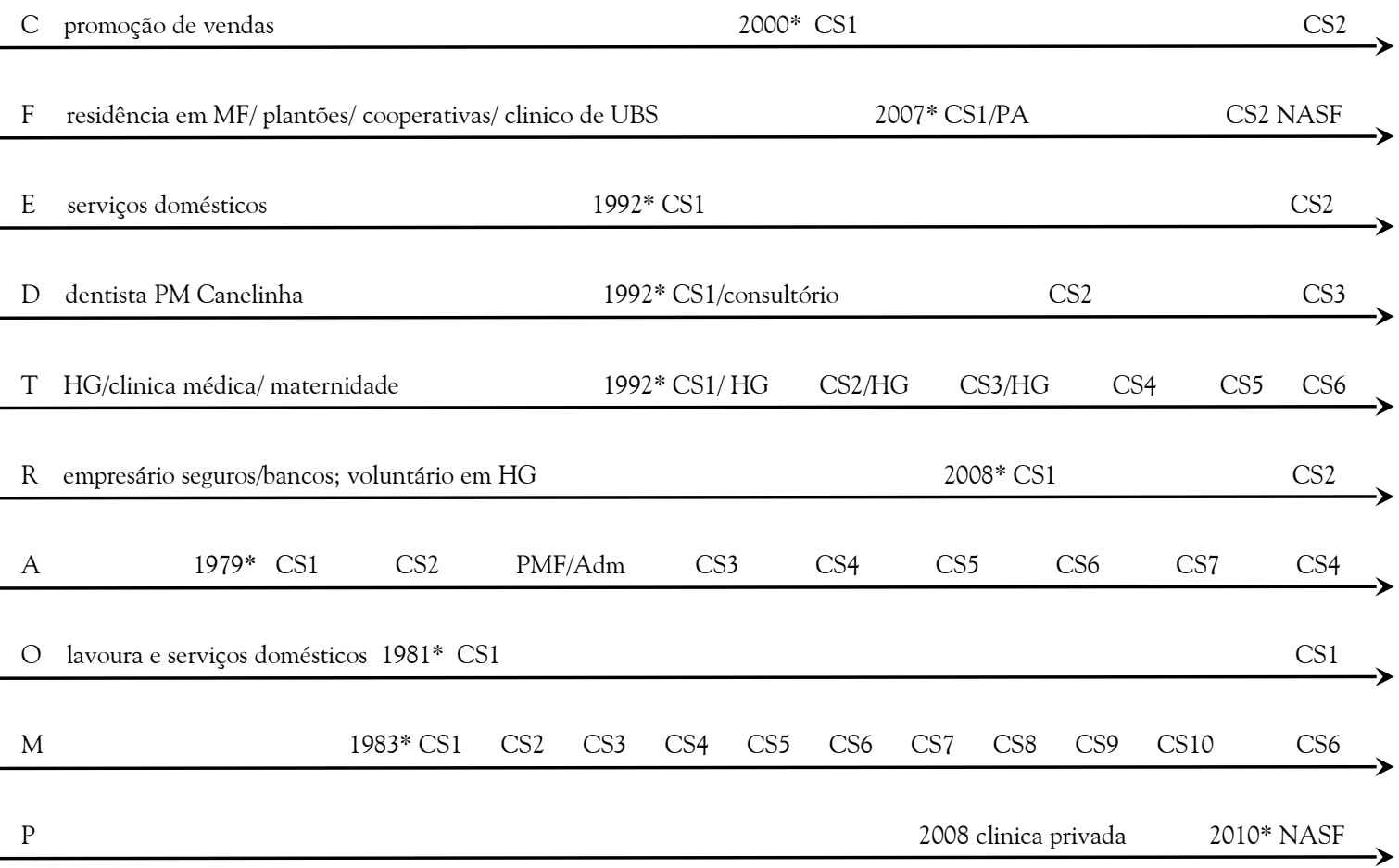

As designações CS1, CS2, CS3, etc indicam as sucessivas unidades nas quais o profissional trabalhou em sua trajetória na PMF. * ano de ingresso na PMF

No relato seguinte, $\mathrm{T}$ compara seu trabalho em dois níveis de atenção diferentes no início de sua carreira, deixando transparecer uma valoração superior ao aprendizado que obtinha em termos tecnológicos a partir de sua experiência em hospital geral, se comparada ao trabalho na atenção básica à saúde:

[...] tu regride um pouco né, porque tu faz o básico no posto de saúde, e no hospital tu tá atualizada sempre que mudam os antibióticos, os de $3^{\underline{a}}$ geração que se fala, que são as mais potentes... eu não sei mais agora os últimos ( $\mathrm{T}$ - técnica de enfermagem).

A atribuição de valores contida nesse tipo de comparação pode expressar certa resistência em abrir mão do modelo tradicional de saúde, acarretando, na prática, dificuldades de adaptação ao modelo de atendimento no nível da atenção básica, especialmente se o profissional não tiver uma qualificação, seja de formação acadêmica prévia ou capacitação posterior na qual tenha tido a chance de atualizar-se e inteirar-se quanto ao modelo de atenção preconizado pelas políticas públicas oficiais de saúde, especificamente a partir das leis que regem o SUS desde 1990 (Brasil, 2000) e o PSF a partir de 1994 (Brasil, 2006). Essas dificuldades referem-se principalmente a uma visão de saúde trazida por profissionais de outros níveis de atenção, predominantemente centrada na hegemonia do modelo biomédico do tratamento e da cura de doenças e não em sua prevenção e na promoção de saúde e atendimento de necessidades integrais dos indivíduos que buscam os centros de saúde.

No que diz respeito às formações dos profissionais, tanto acadêmicas quanto de capacitações posteriores, incluindo especializações, houve pouca associação de seus conteúdos com o trabalho realizado na atenção básica. Dos 10 entrevistados, apenas 3 realizaram cursos, 
sejam introdutórios ou de especialização em saúde da família, como mostrou o Quadro 1. A formação acadêmica, embora seja bastante heterogênea entre si, em geral, é compatível com os cargos que os sujeitos ocupam.

Quanto às qualificações na forma de capacitações voltadas ao exercício das funções, observou-se nos relatos a diversidade de maneiras como se desenvolvem no cotidiano dos profissionais da atenção básica à saúde no município: encontram-se desde cursos de especialização realizados com recursos próprios dos sujeitos, como medicina de família, dentística, terapia cognitivo-comportamental, passando por cursos e treinamentos sobre assuntos específicos oferecidos pelo Município e/ou Estado, como introdução à medicina de família, auxiliar de enfermagem, informação e sistemas, socorrista do corpo de bombeiros e incluem-se, ainda, cursos de atualização em vacinas e curativos, além de capacitações para coordenadores de unidades para implantação de novos programas. Além de todas essas modalidades, também foram citados treinamentos inespecíficos, que ocorrem de maneira espontânea, informal e por iniciativa dos próprios profissionais, quando iniciam o trabalho nos centros de saúde:

Quando eu entrei no Posto de Saúde, a gente aprendeu assim: uma colega ensinava pra outra [...] (C-ACS).

Quando eu entrei aqui, o Doutor me ensinou, [...] me orientou sobre os materiais e eu já fui marcando tudo direitinho, fui fazendo tudo em pacotes... (O - ACO).

Esses relatos sugerem a ausência de um procedimento padrão previamente estabelecido no que diz respeito à existência e/ou exigência de treinamentos e capacitações para a função no momento em que os profissionais entram para trabalhar nas unidades. Essa medida parece ocorrer de modo mais casuístico do que propriamente por uma exigência prévia do Ministério da Saúde, a depender do órgão gestor municipal. Alguns profissionais fazem o movimento no sentido de buscar capacitação, porém, a iniciativa depende muito do próprio interesse e/ou da disponibilidade de tempo e financeira: dos 5 servidores de nível superior entrevistados, 4 buscaram capacitação com recursos próprios. Também não houve referência a incentivos financeiros ou ajuda de custo por parte da prefeitura nesses casos, apenas a dispensa do dia de trabalho, a qual foi referida por D como uma grande vantagem já obtida:

Sou liberada uma vez por semana para especialização, segunda o dia todo, isso é bem legal, eu conseguir liberação. O secretário liberou porque é educação continuada, achei bem importante e bem legal que ele liberou, apesar de não ser promovido pela prefeitura, é pela UFSC, a gente prestou concurso, é gratuita (D - dentista).

Já C refere um curso de iniciação para ACS com duração de quatro meses, atualmente realizado em parceria com a Secretaria de Estado da Saúde como uma espécie de prêmio, expressando em sua narrativa certo orgulho por fazer parte do evento, pois se encontra há 10 anos desenvolvendo essa função, período durante o qual foi oferecido apenas um treinamento "mais longo".

[...] esse curso da EFOS (Escola de Formação em Saúde) que é durante 4 meses... é uma capacitação, $[\ldots]$ no dia que foi apresentado teve um evento lá Secretaria do Estado de Administração, lá foi a aula inaugural que nós tivemos [...] foi um evento que estavam as autoridades, tal (C - ACS).

Foram referidas como iniciativas oficiais tão somente capacitações para implantação de novos programas assumidos pela Prefeitura, como tuberculose e dengue, como um procedimento regular da atual gestão, embora não sejam oferecidas para todas as categorias profissionais, conforme relato de E, que também acumula a função de coordenadora do Centro deSaúde: 
[...] geralmente é mais para o nível superior, o nível médio reclama que fica de fora, não sei se é para não tirar o pessoal da unidade. Agora para assistência farmacêutica chamaram os técnicos, de tanto a gente pedir (E - enfermeira).

Parece haver uma suposição generalizada de que os profissionais, ao entrar nas unidades, têm condições de ir aprendendo na prática com quem já está na ativa há mais tempo, o qual, por sua vez, também aprendeu com alguém anteriormente ou através da própria experiência. T explicita essa prática quando relata sua vivência de ter iniciado sozinha no setor de enfermagem por ocasião da inauguração de um Centro de Saúde, há 18 anos:

Eu cheguei sozinha no Posto, não tinha ninguém comigo, era pequenininho perto da escola (não é $o$ atual). Cheguei sozinha, não tinha ninguém lá para dizer vai fazer isso, vai fazer aquilo, entrei lá e me deixaram sozinha [...] ( $\mathrm{T}$ - técnica de enfermagem).

Sobre a questão relativa às necessidades de capacitação para o trabalho pela via das iniciativas institucionais, Fernandes, Bastos, Tironi e Viana (2006, p. 558) afirmam haver uma crença generalizada de que "treinamento é algo benéfico e necessário, não constituindo custos, mas investimentos organizacionais" e, talvez por isso, as ações de treinamento quase sempre não costumam ser acompanhadas de processos de levantamento de necessidades e de avaliação de impactos. É comum nas organizações, segundo esses autores, a inexistência de um sistema articulado de ações de treinamento, desenvolvimento e educação (TD \& E) que considere todas as etapas necessárias. Segundo Borges-Andrade (2006), um sistema de TD \& E deveria ser integrado de três subsistemas que se complementam de acordo com o contexto organizacional: a avaliação de necessidades; o planejamento e sua execução; e a avaliação do processo. Esse sistema consistiria, portanto, em uma condição ideal, considerando as organizações que tenham autonomia para a implantação de um processo amplo de treinamento, desenvolvimento e educação, utilizando a terminologia do autor. No campo em que se desenvolveu este estudo, segundo publicação do Conselho Nacional de Secretários de Saúde Conass (Brasil, 2009) que avalia a implantação do SUS ao longo dos últimos vinte anos, verifica-se que a gestão de recursos humanos nas secretarias, tanto estaduais quanto municipais, possui uma autonomia relativa e subordina-se setorialmente às secretarias de administração, o que lhes confere certa limitação em seu papel decisório. A esse respeito, a Lei n. 8.090/90, em seu artigo 27, afirma que:

[...] a política de recursos humanos na área da saúde será formalizada e executada, articuladamente, pelas diferentes esferas de governo, em cumprimento de seus objetivos de organização de um sistema de formação de recursos humanos em todos os níveis de ensino, inclusive de pós-graduação, além de elaboração de programas de permanente aperfeiçoamento de pessoal (Brasil, 2009, p. 98).

Para a Norma Operacional Básica sobre Recursos Humanos do SUS - NOB/RH-SUS (Brasil, 2005), instrumento originário do Conselho Nacional de Saúde e consolidado pela 11ạ Conferência Nacional de Saúde, o setor requer a formação de pessoal específico, que disponha do domínio tanto de tecnologias para a atenção individual de saúde como para a saúde coletiva. Para a NOB/RH-SUS, a qualidade da atenção à saúde está relacionada à formação dos profissionais, e a formulação de políticas está relacionada às propostas de formação de novos perfis profissionais (Ceccim \& Feuerwerker, 2004). A formação de novos perfis profissionais, por sua vez, remete à discussão sobre "por quem e onde essa formação deve se dar" para ser mais efetiva no atendimento ao objetivo de melhorar a qualidade da saúde prestada no SUS.

Como espaços de qualificação, Bianchetti (2001) refere-se a estudos de Lúcia Bruno (1996), os quais excluem a esfera do trabalho como primordial na produção de qualificação, como o são a família e as instituições especializadas, sendo a escola a principal, além do meio social urbano. "Com os cursos, treinamentos e reciclagens patrocinados pela esfera do trabalho, 
o máximo que pode ocorrer, segundo a autora, é a potencialização de capacidades e aptidões adquiridas em outras esferas" (Bianchetti, 2001, p. 28).

Ceccim (2004-2005, p. 161), ao discutir a questão da formação e capacitação profissional especificamente no âmbito da saúde, defende a necessidade de "assegurar à área da formação do profissional de saúde não mais um lugar secundário ou de retaguarda, mas um lugar central, finalístico às políticas de saúde" como uma maneira de retirar os trabalhadores da condição de "recursos" e conferir-lhes o status de "atores sociais". A introdução da educação permanente em saúde ${ }^{7}$, segundo esse autor, seria uma estratégia fundamental para o que denomina "o quadrilátero da saúde": a recomposição das práticas de formação, atenção, gestão e formulação de políticas e controle social no setor da saúde. Trata-se de um exemplo de investimento nos microprocessos, nos quais os sujeitos estariam diretamente envolvidos como atores participantes e não apenas como executores de normativas, cujas atividades previstas se dão, na prática, muitas vezes desconectadas de uma visão do todo e das possibilidades de realizações concretas.

Segundo o Conass (Brasil, 2009), a Política Nacional de Educação Permanente (Peps), após longa negociação entre os gestores do sistema, foi reformulada e adequada às diretrizes operacionais e ao regulamento do Pacto pela Saúde pela Portaria GM/MS n. 1.996/2007, tendo sido implantada até setembro de 2008 em 19 estados nacionais. Algumas ações são citadas como parte dessa iniciativa em diversos níveis: na Graduação foram instituídos um programa nacional, o Pró-Saúde e o Programa de Educação Tutorial (PET-Saúde) visando a promover e financiar mudanças na formação de diversos cursos por meio da integração ensino-serviço; na Pós-Graduação destaca-se a criação da residência multiprofissional em saúde, estendida para outras profissões, além da medicina; além disso, a especialização em serviço e a residência em medicina de família e comunitária, voltada à formação de profissional médico mais adequada às necessidades do sistema público de saúde. Na área técnica, a qualificação ofereceu um avanço com o Projeto de Profissionalização dos Trabalhadores da Área de Enfermagem (Profae), o qual qualifica técnicos de enfermagem. Além desse Projeto há, também, a oferta do Programa de Formação Profissional na Área de Saúde (Profaps), cujo objetivo é qualificar trabalhadores, dentre eles agentes comunitários de saúde e auxiliares de consultório odontológico, além de técnicos de enfermagem, manutenção de equipamentos, vigilância sanitária, epidemiológica e ambiental, em cursos de educação profissional para o setor saúde, já inseridos ou a ser inseridos no SUS ao longo dos próximos oito anos (Brasil, 2009).

Uma referência às capacitações oferecidas pela esfera governamental, comparada ao proposto pelas Peps, foi feita pelos sujeitos E, C e A (Quadro 1) como tendo sido oferecidas após sua inserção no quadro da PMF, respectivamente, para realizar os cursos de iniciação de saúde da família, de agente comunitário de saúde e de auxiliar de enfermagem. O curso de medicina de família e residência multiprofissional citados por $\mathrm{F}$ foram realizados anteriormente ao seu ingresso na PMF. Já, a especialização que D está cursando atualmente é oferecida pela universidade, tendo sido opção e iniciativa sua cursá-la. Percebeu-se, então, que, dependendo do cargo, o nível de exigência de qualificação se torna maior e mais específico para admissão na PMF para compor o quadro de trabalhadores da atenção básica e PSF.

No relato seguinte evidencia-se outro tipo de expressão de necessidade, não restrita somente à reciclagem técnica, mas que aparece mesclada com aspectos motivacionais relacionados ao trabalho no dia a dia:

7 A escolha da designação educação permanente em saúde e não apenas educação permanente se deu em função de que, como vertente pedagógica, essa formulação ganhou o estatuto de política pública apenas na área da saúde. Esse estatuto se deveu à difusão, pela Organização Pan-Americana da Saúde, da proposta de educação permanente do pessoal de saúde para alcançar o desenvolvimento dos sistemas de saúde na região com reconhecimento de que os serviços de saúde são organizações complexas em que somente a aprendizagem significativa será capaz da adesão dos trabalhadores aos processos de mudança no cotidiano (Ceccim, 2004-2005, p. 161). 
Quando a gente sai da unidade dá um alívio, né? O pessoal tá sempre aqui, sempre a mesma coisa, todo dia... pra mim é bom, que eu sou coordenadora, porque de vez em quando eu estou fora. Quando eu venho pra cá eu venho com mais vontade, eu tenho que me renovar (E - enfermeira).

A saída da unidade de saúde para capacitações aparece na narrativa acima como uma maneira de atenuar a rotina diária de trabalho e, ao mesmo tempo, como uma forma de renovação da própria motivação para a continuidade do trabalho. Esse dado vai ao encontro da contribuição de Borges-Andrade (2006), que coloca como indicadores de efeitos de TD \& E em longo prazo, no nível individual, aspectos relativos ao afeto e à cognição entre outros, que incluem atitudes diante das pessoas, autoeficácia, bem-estar mental, uso de informações verbais, solução de problemas, além de criatividade e motivação no trabalho. Aspectos motivacionais gerados através do pensamento, para a psicologia sócio-histórica, estão intimamente ligados a desejos e necessidades, interesses e emoções, e, portanto, não podem estar desvinculados entre si, reforçando a tendência afetivo-volitiva por trás de cada um deles (Aguiar, 2009).

As experiências que os sujeitos vivenciam e trazem consigo fazem parte de sua bagagem pessoal e profissional, tornando-se determinantes de sua visão acerca do trabalho na saúde, bem como das relações estabelecidas nele e para com ele, contribuindo para a configuração dos seus sentidos. Ao relatar sua experiência anterior em hospitais, T reforça o aspecto da inovação no trabalho nesse nível de atenção, se comparado ao trabalho na atenção básica, que define como mais rotineiro:

A única coisa é que no hospital é mais cansativo, é o plantão de sábado, domingo, feriado, mas lá é mais fácil para trabalhar; porque, assim, são pacientes muito diferentes, e aqui são sempre os mesmos, nós temos pacientes aqui que vêm todo dia e não têm necessidade de vir, mas todo dia vêm, e isso aí cansa. No hospital é diferente, aqui é sempre a mesma rotina, não muda muito $[. .$.$] ( \mathrm{T}$ - técnica de enfermagem).

Em outro momento de sua narrativa, porém, ela pondera que no trabalho na atenção básica são necessárias outras habilidades, do campo das inter-relações mediadas pela linguagem, mais especificamente no exercício da dialogicidade e subjetividade humanas, presente na sua relação com o usuário do serviço de saúde.

Nos dias que tem mais tempo às vezes penso em sentar mais, conversar mais, ensinar, é ensinar [...], é porque não basta você chegar ver a pressão, coloca no braço do paciente, sua pressão tá boa, ou tá alta, tchau e pronto, senão a coisa se torna mecânica [...] (T — técnica de enfermagem).

Pereira e Barros (2008) afirmam essa natureza conversacional do trabalho em saúde, bem como reforçam a presença de uma experimentação conectiva/afetiva entre os diferentes sujeitos que participam do processo de produção de saúde. Em outra passagem, a mesma trabalhadora refere-se, sem se dar conta, a certa imprevisibilidade do trabalho no centro de saúde, fugindo à rotina referida anteriormente, momento no qual a subjetividade do profissional evidencia-se diante da resolução de determinadas situações, a partir do diálogo e da concretude de suas ações:

Outro dia chegaram dois rapazes para pegar medicação com um menino bem gordinho e eu pensei "eu preciso chegar nesse menino, preciso fazer a minha parte", mas do outro lado eu não tive resposta. Eu disse pra ele "você não me leve a mal, mas tu não gostarias de participar, a gente tem um trabalho de reeducação alimentar, de hipertenso, diabético, tu estuda?" [...] ( $\mathrm{T}$ - técnica de enfermagem). 
Observa-se certa contradição quanto ao modo como define seu trabalho no centro de saúde como básico e rotineiro, por um lado, e imprevisível por outro, quanto às possibilidades de inserção profissional a partir de uma visão mais abrangente do que venha a ser seu papel na atenção básica também como agente de promoção de ações em saúde, transcendendo, desse modo, uma função meramente técnica.

A visão de homem na concepção sócio-histórica, cuja identidade é cunhada socialmente, pressupõe uma incessante transformação pela ação. Tomado em seu sentido genérico, o homem, segundo Pino (1993, p. 51) "é o resultado da atividade de trabalho através da qual, ao mesmo tempo que transforma a natureza para atender suas necessidades básicas, transforma-se a si mesmo, desenvolvendo funções especificamente humanas (funções mentais e habilidades técnicas)". Acrescenta-se aqui a visão que Vygotski (1991) desenvolve a respeito da subjetividade humana com base em seus aspectos afetivo-volitivos, pressupondo que esses aspectos se encontram implícitos em todas as ações humanas, produzindo sentidos a estas através da linguagem como síntese do pensamento. A presença da subjetividade nos remete ao pressuposto de que as ações humanas relativas ao trabalho cotidiano estejam intimamente relacionadas às motivações e aos afetos, sendo determinadas e determinantes destes, permeando todas as relações e mediadas pela linguagem.

Retornando ao contexto no qual $\mathrm{T}$ e sua atividade de trabalho são confrontadas, duas dimensões fazem-se presentes: a subjetiva de um e a objetiva do outro, tornando essa relação única e singularmente real, o que a torna diferente de outra ação com o mesmo propósito realizada por qualquer outro profissional com a mesma formação em outra unidade de saúde e, consequentemente, diferenciada também em sua atribuição de sentidos. Essas duas dimensões encontram-se interligadas no trabalho em saúde, fazendo parte do modo como os profissionais vivenciam o processo de trabalho na atenção básica, contribuindo para a composição de sua identidade pessoal, de um lado, e enquanto parte de um grupo social, de outro. A constatação de que sujeitos relacionam-se e atribuem sentidos à suas atividades de maneira singular é corroborada por Zanella (2004, p. 130) ao referir que "os sujeitos em relação atribuem sentidos diferentes àquilo que vivenciam".

Quanto aos modos de encarar o trabalho e de lhe atribuir sentidos, não podia ser diferente, observando-se as motivações contidas nos relatos que se produzem tanto na ordem do ser humano em sua dimensão individual/particular...

[...] de modo geral faz parte da minha vida, sempre trabalhei desde criança. [...] eu nasci pra isso. Fui criada, condicionada pra trabalhar (E - enfermeira do PSF).

[...] é minha profissão, né, minha sobrevivência, é minha profissão ( $M$ - pediatra).

... como nas duas dimensões, a individual/particular atrelada à dimensão humana/genérica, indicando uma reflexão sobre a função social e ideológica do trabalho em si. Essa reflexão está presente nos relatos abaixo:

[...] quando você entra na Prefeitura você quer um emprego, né, salário fixo, todos os direitos, mas tem que ir além disso [...] Eu acho que tem tudo a ver, a saúde no serviço público, você oferecer isso para o povo, então, pra mim é totalmente o que eu quero. Bem onde eu quero trabalhar e no que eu acredito (D - dentista).

O trabalho pra mim é fonte de renda e de realização pessoal [...] acho que aqui, o retorno pra população é maior, é atendimento gratuito, todas as pessoas, teoricamente, têm acesso a ele [...] ( $\mathrm{P}$ - psicóloga).

Para Heller (1989, p. 20), "a vida cotidiana é a vida do indivíduo" sendo este "sempre, simultaneamente, ser particular e ser genérico". A possibilidade de refletir sobre o próprio 
trabalho pode encontrar-se comprometida pela cotidianidade das ações, ocasião na qual os aspectos da ordem do individual/particular dos sujeitos podem estar desarticulados de sua porção humana/genérica. Sendo assim, o trabalho, como parte da estrutura da vida cotidiana, pode constituir-se em um terreno fértil para a alienação. Com o fim das comunidades naturais e o advento das comunidades sociais, segundo Heller (1989, p. 23), "aumentam as possibilidades que têm a particularidade de submeter a si o humano/genérico e de colocar as necessidades e interesses da integração social em questão a serviço dos afetos, dos desejos, do egoísmo do indivíduo". A possibilidade de uma vitória espontânea da particularidade sobre o humano/genérico trouxe a questão ética como uma necessidade da comunidade social. Essa ética, chamada de moral, é individual e tida como motivação para a atitude livremente adotada pelos indivíduos perante a sociedade e os homens.

Nesse sentido, em relação ao fato de este trabalho desenvolver-se no setor público, resgata-se o que Chanlat (2002) aponta sobre a necessidade das ações públicas estarem direcionadas a uma ética do bem comum, na qual o funcionário público deveria deixar de lado suas posições pessoais. Aspectos do ser humano particular devem integrar-se, nesse caso, a aspectos do ser humano genérico, de modo a contemplar essa ética.

Retomando o conteúdo das narrativas que trazem respostas à atribuição de sentidos ao trabalho de modo mais amplo, observou-se que os sujeitos E, M, D e P circularam de modos bastante singulares entre suas porções particulares e genéricas, utilizando a terminologia de Heller (1989). A própria entrevista de pesquisa parece ter proporcionado-lhes uma possibilidade concreta de reflexão acerca desses sentidos, trazendo como resultados os diferentes sentidos assumidos pelo trabalho em suas vidas, envolvendo questões relativas à formação pessoal, criação familiar, condicionamento pessoal, profissão, sobrevivência, emprego, fonte de renda, realização pessoal, a crença no serviço público e a possibilidade de devolução do investimento na formação à sociedade.

A análise das narrativas, em síntese, mostrou quem são os sujeitos que trabalham na atenção básica, incluindo suas trajetórias profissionais e o que pensam sobre o trabalho que realizam. Essas narrativas demonstraram um grande envolvimento desses trabalhadores com suas práticas, o que as tornam indissociáveis e centrais em suas vidas, fazendo parte da construção de suas múltiplas e indissociáveis identidades, pessoal, profissional e social, enquanto parte de um grupo de trabalho específico de trabalhadores da atenção básica à saúde. Quanto à formação acadêmica para os cargos ocupados, são na maioria das vezes compatíveis no que diz respeito ao grau de escolarização exigido, porém, o investimento em qualificação para as funções desenvolvidas acaba ficando muito por conta do profissional, individualmente, o que é corroborado pela literatura.

No que diz respeito às capacitações formais, como cursos de especialização e de atualização, aquelas oferecidas pelo órgão gestor são referidas como iniciativas não padronizadas, causando uma impressão de aleatoriedade e de sujeição a interferências de ordem política que geram um redirecionamento nos projetos a cada mudança de gestão. Capacitações mais longas, em nível de especialização são realizadas geralmente pelos profissionais de nível superior e com recursos próprios, sendo que os profissionais de nível médio ficam sujeitos à oferta desse tipo de qualificação por parte do órgão gestor, em uma postura de certa forma passiva, à espera de recursos e iniciativas alheias. Apesar da existência de programas oficiais de educação permanente voltados à formação em saúde, observa-se que, nos quadros da SMS/PMF, muitos profissionais ainda não possuem capacitação prévia para a função que vão desenvolver na atenção básica. Esse fator pode gerar certo conflito de intenções, no que diz respeito à compreensão dos objetivos e do modo de organização dos serviços nas unidades de saúde nesse nível de atenção, por mais identificação e compromisso com o trabalho que os profissionais possam estabelecer. 


\section{Considerações finais}

Os achados da pesquisa em relação "a quem são os profissionais da atenção básica, em que contexto de trabalho se inserem e, se escolheram ou foram escolhidos para desenvolver esse tipo de trabalho", mostraram uma inter-relação entre as dimensões singular e coletiva dos sujeitos que o realizam, que os inserem em um contexto de trabalho e de vida em estreita ligação. Observou-se neste estudo uma profunda identificação desses sujeitos com suas atividades de trabalho.

A maioria teve sua trajetória profissional relacionada à área da saúde desde o início da carreira. Mesmo aqueles que não passaram por experiência anterior na saúde não demonstraram insatisfação ou arrependimento pela escolha da área atual de trabalho.

Em relação à qualificação para o trabalho e à pergunta colocada no início do estudo "como lidam com a discrepância entre sua formação profissional e as demandas e modelos de atuação da atenção básica?" encontrou-se: no que tange à capacitação para as funções desenvolvidas nos centros de saúde, parece estar naturalizado entre os trabalhadores o modo de ir aprendendo na prática com quem já está na ativa há mais tempo, o(a) qual, por sua vez, também já aprendeu com alguém anteriormente ou através da própria experiência. Não obstante essa "naturalização", evidenciou-se um anseio por capacitações não apenas no nível técnico de suas funções, mas também como oportunidades de reciclagem pessoal ou mesmo do simples fato de sair da unidade e manter contato com outros profissionais em situações que fujam à rotina de trabalho. A iniciativa de capacitação, quando não proporcionada pelo órgão gestor, é buscada pelo profissional, geralmente por aqueles de nível superior, por sua própria conta. Já os profissionais de nível médio comumente esperam por uma oportunidade que seja oferecida pelo próprio órgão gestor, seja organizada pela Prefeitura ou, ainda, através de parcerias com o Estado, na forma de capacitações e treinamentos específicos.

Destaca-se a ausência de um procedimento padrão previamente estabelecido relativo a treinamentos e capacitações para os respectivos cargos no momento em que os profissionais ingressam para trabalhar na atenção básica, sendo esses cursos ofertados ocasionalmente e de modo assistemático, a depender da política de gestão e da necessidade momentânea.

O trabalho, de modo geral, foi trazido com diferentes sentidos, variando a partir de uma valorização de dimensões mais particulares determinantes de suas trajetórias profissionais relativas à formação pessoal, criação familiar, condicionamento pessoal, profissão, sobrevivência, emprego, fonte de renda e realização pessoal. Valores mais humanos/genéricos também foram citados em menor escala como sentidos atribuídos ao trabalho, relacionados ao serviço no setor público, como acreditar no trabalho no serviço público e a possibilidade de devolver à sociedade o investimento realizado na formação universitária.

Embora suas trajetórias de trabalho tenham se mostrado em suas singularidades, em alguma medida os profissionais também se reconhecem enquanto participantes de um coletivo de trabalho, com a necessidade de se movimentar entre essas duas dimensões em seu cotidiano de trabalho, reafirmando o imbricamento de suas porções humanas/genéricas e individuais/particulares em todo o processo.

A presença de duas dimensões constata-se o tempo todo no trabalho nesse nível de atenção: a subjetiva de um e a objetiva do outro, tornando essa relação única e singularmente real, o que a diferencia de outra ação com o mesmo propósito realizada por qualquer outro profissional com a mesma formação em outra unidade de saúde, e, consequentemente, diferenciada também em sua atribuição de sentidos. No entanto, aspectos presentes no processo de trabalho nesse nível de atenção, como dialogicidade e subjetividade humanas, conectividade e afetividade vêm fazer parte da composição deste como coletivo de trabalho, 
com uma identidade que os aproxima e acumplicia enquanto grupo, embora sua prática seja expressa singularmente pelos sujeitos que a executam.

Por outro lado, a mesma singularidade que diferencia quem e como se realiza o trabalho na atenção básica, promove uma aproximação enquanto grupo de trabalho inserido em um contexto coletivo que os identifica. Em síntese, fazem parte desse processo identificatório: as respectivas trajetórias profissionais, as diversificadas qualificações integradas às experiências de vida dos sujeitos, além do modo singular como cada um atribui sentidos ao seu trabalho e o exerce em suas múltiplas relações entre aspectos objetivos e subjetivos, evidenciadas pelas exigências do processo individual/coletivo de trabalho em saúde na atenção básica.

\section{Referências}

Aguiar, W. M. J. (2009). Consciência e atividade: categorias fundamentais da psicologia sócio-histórica. In A. M. B. Bock, M. G. M. Gonçalves, O. Furtado (Org.), Psicologia sócio-histórica: uma perspectiva crítica em psicologia (4ºd., pp. 96-110). São Paulo: Cortez.

Aguiar, W. M. J. \& Ozella, S. (2006). Núcleos de significação como instrumento para a apreensão da constituição dos sentidos. Psicologia: Ciência e Profissão, 26 (2), 222-245.

Antunes, R. (1999, dezembro). O mundo precarizado do trabalho e seus significados. Cadernos de Psicologia Social do Trabalho, 2, 55-59.

Berger, P. \& Luckmann, T. (1999). A construção social da realidade. Petrópolis, RJ: Vozes.

Bianchetti, L. (2001). Da chave de fenda ao laptop. In L. Bianchetti, Tecnologia digital e novas qualificações: desafios à educação (pp. 19-30). Petrópolis, RJ: Vozes.

Bruno, L. (1996) (Org.). Educação e trabalho no capitalismo contemporâneo. São Paulo: Atlas.

Borges-Andrade, J. E. (2006). Avaliação integrada e somativa em TD \& E. In J. E. Borges-Andrade, G. S. Abbad, L. Mourão (Org.), Treinamento, desenvolvimento e educação em organizações e trabalho: fundamentos para a gestão de pessoas (pp. 343-358). Porto Alegre: Artmed.

Brasil. (2000). Sistema Único de Saúde (SUS): princípios e conquistas. Brasília, DF: Ministério da Saúde.

Brasil. (2005). Princípios e diretrizes para a gestão do trabalho no SUS: NOB/RH-SUS (3aㅡ ed. rev. e atual.). Brasília, DF: Ministério da Saúde.

Brasil. (2006). Portaria n. 648, 28 de março de 2006. Brasília, DF: Ministério da Saúde.

Brasil. (2008). Portaria n. 154, 24 de janeiro de 2008. Brasília, DF: Ministério da Saúde.

Brasil. (2009). SUS 20 anos (pp. 93-114). Brasília, DF: Conselho Nacional de Secretários de Saúde.

Campos, G. W. S. \& Domitti, A. C. (2007). Apoio matricial e equipe de referência: uma metodologia para gestão do trabalho interdisciplinar em saúde. Cadernos de Saúde Pública, 23 (2), 399-407.

Ceccim, R. B. (2004-2005, setembro/fevereiro). Educação permanente em saúde: desafio ambicioso e necessário. Interface: Comunicação, Saúde, Educação, 9 (16), 161-177.

Ceccim, R. B. \& Feuerwerker, L. C. M. (2004). Mudança na graduação das profissões de saúde sob o eixo da integralidade. Cadernos de Saúde Pública, 20 (5), 1400-1410.

Chanlat, J. F. (2002). O gerencialismo e a ética do bem-comum: a questão da motivação para o trabalho nos serviços públicos. In Anais de VII Congreso Internacional del CLAD sobre la Reforma del Estado y de la Administración Pública (pp. 8-11). Lisboa, Portugal: [s. n.].

Ciampa, A. C. (1984). Identidade. In: S. T. M. Lane \& W. Codo (Org.), Psicologia Social: o homem em movimento (pp. 58-75). São Paulo: Brasiliense.

Ciampa, A. C. (1987). A estória do Severino e a história da Severina: um ensaio de Psicologia Social (pp. 197-201). São Paulo: Brasiliense.

Coutinho, M. C. (2006). Participação no trabalho. São Paulo: Casa do Psicólogo. 
Coutinho, M. C. (2009). Sentidos do trabalho contemporâneo: as trajetórias identitárias como estratégia de investigação. Cadernos de Psicologia Social do Trabalho, 12 (2), 189-202.

Coutinho, M. C., Krawulski, E. \& Soares, D. H. P. (2007). Identidade e trabalho na contemporaneidade: repensando articulações possíveis. Psicologia E̊ Sociedade, 19 (especial 1), 29-37.

Elman, C. (2005). Reflexões de uma equipe multiprofissional que desenvolve reabilitação pulmonar acerca de seu processo de trabalho. Dissertação de Mestrado, Programa de Pós-Graduação em Enfermagem, Universidade Federal de Santa Catarina, Florianópolis.

Fermino, J. M., Patrício, Z. M., Krawulski, E. \& Sisson, M. C. (2009). Atuação de psicólogos no Programa de Saúde da Família: o cotidiano de trabalho oportunizando repensar a formação e as práticas profissionais. Aletheia, 30, 113 128.

Fernandes, S. R. P., Bastos, A. V. B., Tironi, M. O. S. \& Viana, A. C. V. (2006). "Cuidar-se para cuidar": avaliação de um programa de desenvolvimento de pessoas de um hospital. In J. E. Borges-Andrade, G. S. Abbad, L. Mourão (Org.), Treinamento, desenvolvimento e educação em organizações e trabalho: fundamentos para a gestão de pessoas (pp. 558-570). Porto Alegre: Artmed.

Freitas, M. T., Souza, S. J. \& Kramer, S. (Org.). (2007). Ciências humanas e pesquisa: leituras de Mikhail Bakhtin (2a ed.). São Paulo: Cortez.

Gonçalves, R. B. M. (1994). Tecnologia e organização social das práticas de saúde: características tecnológicas do processo de trabalho na rede estadual dos centros de saúde de São Paulo. São Paulo: Hucitec-Abrasco.

Gonzalez-Rey, F. (1999). La investigación cualitativa en Psicología: rumbos y desafíos. São Paulo: Educ.

Guimarães, N. A. \& Hirata, H. (2006). Desemprego: trajetórias, biografias, mobilizações. São Paulo: Senac.

Heller, A. (1989). O cotidiano e a história (3a ed.). São Paulo: Paz e Terra.

Jacques, M. G. C. (1993). Trabalho, educação e construção da identidade. Tese de Doutorado, Programa de PósGraduação em Educação, Pontifícia Universidade Católica do Rio Grande do Sul, Porto Alegre.

Jacques, M. G. C. (1996). Identidade e trabalho: uma articulação indispensável. In: A. Tamayo, J. E. BorgesAndrade \& W. Codo (Org.), Trabalho, organizações e cultura (pp. 41-47). São Paulo: Cooperativa de Autores Associados.

Jacques, M. G. C. (2006). Identidade e trabalho. In: A. D. Cattani \& L. Holzmann (Org.), Dicionário de trabalho e tecnologia (pp. 155-157). Porto Alegre: UFRGS.

Krawulski, E. (1998). A orientação profissional e o significado do trabalho. Revista da Associação Brasileira de Orientadores Profissionais, 2 (1), 5-19.

Martin-Baró, I. (1988). Sistema, grupo y poder: psicologia social desde Centro-América II. San Salvador, El Salvador: UCA.

Martins, S. A. C. (2011). Cotidiano de trabalho de profissionais da atenção básica à saúde: uma "arena" de sentidos, emoções, saberes e fazeres. Dissertação de Mestrado, Programa de Pós-Graduação em Psicologia da Universidade Federal de Santa Catarina, Florianópolis.

Merhy, E. E. \& Franco, T. B. (2008). Reestruturação do trabalho em Saúde. In I. B. Pereira \& J. C. França Lima (Orgs.), Dicionário da educação profissional em saúde (pp. 349-352, 2ª ed. ampl.). Rio de janeiro: EPSJV.

Pereira, E. H. P. \& Barros, R. D. B. (2008). Humanização. In I. B. Pereira \& J. C. França Lima (Org.), Dicionário da educação profissional em saúde (2ª ed., pp. 243-248). Rio de Janeiro: Escola Politécnica de Saúde Joaquim Venâncio.

Pino, A. (1993). A interação social: a perspectiva sócio-histórica. In M. L. Alves (Org.), Construtivismo em revista (Série Ideias, vol. 20, pp. 49-58). São Paulo: Fundação para o Desenvolvimento da Educação.

Santos, B. S. (2001). Pela mão de Alice: o social e o político na pós-modernidade (8a ed.). São Paulo: Cortez.

Spagnuolo, R. S. \& Guerrini, I. A. (2004-2005, setembro/fevereiro). A construção de um modelo de saúde complexo e transdisciplinar. Interface: Comunicação, Saúde, Educação, 9 (16), 191-194.

Szymanski, H. (2000). Entrevista reflexiva: um olhar psicológico para a entrevista em pesquisa. Psicologia da Educação, 10 (11), 193-215.

Veriguine, N. R., Basso, C., Krawulski, E., Coutinho, M. C. \& Soares, D. H. P. (2011). O método de pesquisa trajetória no trabalho e processos identitários. In Anais da I Jornada Internacional de Práticas Clínicas no Campo Social (pp. 1-9). Maringá, PR: UEM.

Vygotski, L. (1991). A formação social da mente (4a ed.). São Paulo: Martins Fontes. 
Zanella, A. V. (2004). Atividade, significação e constituição do sujeito: considerações à luz da psicologia históricocultural. Psicologia em Estudo, 9, 127-135.

\section{Endereço para correspondência}

selmacaselli@yahoo.com.br, edite@cfh.ufsc.br

Recebido em 14/07/2011

Revisado em 03/04/2012

Aprovado em 11/04/2012 